\title{
The birth of the Journal of Muscle Research
}

\author{
Richard Tregear
}

Received: 24 October 2008/Accepted: 30 October 2008/Published online: 28 November 2008

(C) Springer Science+Business Media B.V. 2008

In the late 1970s a great number of new concepts and techniques were being applied to the study of biological motion at the macromolecular level. Chris Ashley and I had dreamed up the idea of a journal in which we could bring together papers from as wide as possible a range within the field, in the belief that it would improve contact and speed discovery. We were fortunate to get the backing of Chapman and Hall and were able to start publication in 1980 , with high quality printing and regular publication promised. We immediately had, and continued to have, a splendid supply of manuscripts. From the start we tried to keep a good balance between full-length original papers, reviews of particular fields, and abstracts from past research society meetings. Of these it was to me the first two that always mattered the most, because there was the scene potentially changed. However, abstracts had and continue to have their place, since we cannot all go to all the meetings!
Looking back, it is quite odd to realise how quickly the journal became established; it obviously did fulfil a need. I felt then and feel now that the standard of printing and illustration was an important factor in its early success; molecular biology is essentially graphic in both its evidence and its explanations. I note with pleasure that the graphics of the current issues remain of a high standard, as indeed does the whole presentation.

An Editorial Board was formed soon after the journal was started so that not all the work fell on the editor himself, but in practice a great deal did and I think must. The main result of this in the journal's case was a rotation of the editorship between individuals; we had our own research to think about! I very much enjoyed the work, which kept me in contact with so many people and so many ideas, but I was glad not to do it for too long. I am delighted to see that the journal is ploughing on, and wish it and all who write in it the best of good luck.

R. Tregear $(\square)$

79 Gough Way, Cambridge CB3 9LN, UK

e-mail: richard1@ tregearr.freeserve.co.uk 